\title{
Home birth without skilled attendants despite millennium villages project intervention in Ghana: insight from a survey of women's perceptions of skilled obstetric care
}

Emmanuel Kweku Nakua ${ }^{1 *}$, Justice Thomas Sevugu ${ }^{1,4}$, Veronica Millicent Dzomeku ${ }^{3}$,Easmon Otupiri ${ }^{1}$, Heather R. Lipkovich ${ }^{2}$ and Ellis Owusu-Dabo 5,6

\begin{abstract}
Background: Skilled birth attendance from a trained health professional during labour and delivery can prevent up to $75 \%$ of maternal deaths. However, in low- and middle-income rural communities, lack of basic medical infrastructure and limited number of skilled birth attendants are significant barriers to timely obstetric care. Through analysis of self-reported data, this study aimed to assess the effect of an intervention addressing barriers in access to skilled obstetric care and identified factors associated with the use of unskilled birth attendants during delivery in a rural district of Ghana.
\end{abstract}

Methods: A cross-sectional survey was conducted from June to August 2012 in the Amansie West District of Ghana among women of reproductive age. Multi-stage, random, and population proportional techniques were used to sample 50 communities and 400 women for data collection. Weighted multivariate logistic regression analysis was used to identify factors associated with place of delivery.

Results: A total of 391 mothers had attended an antenatal care clinic at least once for their most recent birth; $42.3 \%$ of them had unskilled deliveries. Reasons reported for the use of unskilled birth attendants during delivery were: insults from health workers (23.5\%), unavailability of transport (21.9\%), and confidence in traditional birth attendants (17.9\%); only $7.4 \%$ reported to have had sudden labour. Other factors associated with the use of unskilled birth attendants during delivery included: lack of partner involvement aOR $=0.03(95 \% \mathrm{Cl} ; 0.01,0.06)$, lack of birth preparedness aOR $=0.05(95 \% \mathrm{Cl} ; 0.02,0.13)$ and lack of knowledge of the benefits of skilled delivery $\mathrm{aOR}=0.37(95 \% \mathrm{Cl} ; 0.11,1.20)$.

Conclusions: This study demonstrated the importance of provider-client relationship and cultural sensitivity in the efforts to improve skilled obstetric care uptake among rural women in Ghana.

Keywords: Maternal health, Rural, Millennium Villages Project, Skilled birth attendance

\footnotetext{
* Correspondence: emmanngh@gmail.com

'School of Public Health, Department of Population, Family and

Reproductive Health, Kwame Nkrumah University Science and Technology,

PMB, Kumasi, Ghana

Full list of author information is available at the end of the article
} 


\section{Background}

In low- and middle-income countries (LMICs), majority of births in rural areas occur outside a healthcare facility without skilled obstetric care $[1,2]$. In rural areas of Ghana, 45 - $46.1 \%[3,4]$ of births are overseen by skilled birth attendants (a doctor, physician assistant, midwife or nurse). For the estimated $55 \%$ of women who do not receive skilled attendance at birth, this care comes largely from traditional birth attendants (TBAs, $30 \%)$ and relatives and friends (25\%) [3].

In contrast, more than $80 \%$ of births by women in urban areas are supervised [4] by skilled birth attendants. Consequently, urban maternal mortality is markedly lower than that in rural communities [5]. Unskilled birth attendance is a major obstacle preventing the attainment of MDG 5 which seeks to reduce maternal mortality in LMICs [6]. About $75 \%$ of rural maternal deaths are due to; haemorrhage, eclampsia, obstructed labour and puerperal sepsis as direct causes [6]. A substantial proportion of these deaths are preventable through appropriate and timely interventions, particularly improved access to health facility based intrapartum care $[7,8]$.

In Ghana, expectant mothers benefit from the National Health Insurance Scheme (NHIS) that covers the cost of all maternity services [9]. Insured women are more likely to seek medical care when ill than those not insured with the NHIS [10]. However, in most rural communities lack of skilled personnel in these health facilities and skilled obstetric care services negate the possible benefits of the NHIS. This often results in avoidable or otherwise preventable maternal death [11]. To combat this disparity, the Millennium Villages Project (MVP) designed a strategic model targeted at deprived communities to mitigate some of these inherent problems unique to rural areas in LMICs. The MVP sought to improve the living standards of rural communities through the coordinated and simultaneous delivery of proven package of interventions in health, agriculture, infrastructure and education [12].

This study aimed to assess the effect of an intervention by the MVP that was expected to address barriers to accessing skilled obstetric care and to identify factors associated with the use of unskilled birth attendants during delivery in a rural district of Ghana.

\section{Methods}

\section{Setting}

This cross sectional study, was carried out over the period June - August 2012, in the Amansie West District, a rural district located in the south-western part of the Ashanti Region of Ghana. Amansie West is one of the 30 administrative districts in the Ashanti Region, and one of the most deprived [13]. The district has seven (7) sub-districts with 162 communities. Amansie West district has only one health facility capable of offering comprehensive emergency obstetric care; this facility is far from the reach of many expectant mothers [14]. The district has 54 traditional birth attendants (TBAs) who conduct deliveries in the communities.

The study sites were communities in seven subdistricts including Keniago and Tontokrom, which received the intervention package from the Millennium Village's Project (MVP) in 2006. A baseline assessment of skilled deliveries in these sub-districts was conducted prior to the inception of MVP with a reported, skilled delivery rate of $29 \%$ [15]. The intervention package consisted of; construction of health centres, improved road infrastructure, and the provision and support of health staff (midwives, laboratory technologists, laboratory assistants, pharmacy technicians) to the health centres. In addition, MVP deployed health workers and health care assistants to the communities to provide free antenatal care $[\ldots$...RE $]$.

\section{Sampling and survey}

A sample size of 400 mothers was estimated based on $40.9 \%$ reported skilled deliveries in the district [14] with $5 \%$ degree of error and $10 \%$ non-response rate.

A multi-stage sampling method was used (Fig. 1). First, communities were selected by simple random sampling technique. The seven (7) sub-districts were then listed and 50 out of 162 communities in the district were randomly selected, out of which 15 were from the MVP intervention sub-districts. The second stage of selection involved sampling from a census list of local health officials-Community Health volunteers $(\mathrm{CHW})$ and child welfare clinic personnel (CWC). Data obtained from the community health volunteers ensured that unskilled deliveries were captured. The two lists were put together and checked for consistency. The eligible study population was identified and a sampling frame (6,402 women attending post-partum care) from which mothers with children under-12 months were selected for inclusion from each community was prepared. Mothers aged 15-49 years in each community who had given birth in the year preceding the survey were eligible for inclusion in the study. Finally, the study participants were selected from the sampling frame from the 50 communities; we ensured representation from different age groups using a sampling proportional to size approach for each sub-district.

\section{Data collection}

A structured questionnaire was used to collect data on participants' socio-demographics, antenatal and postnatal care attendance. Also knowledge of the benefits of skilled delivery, and reasons for use or non-use of skilled 


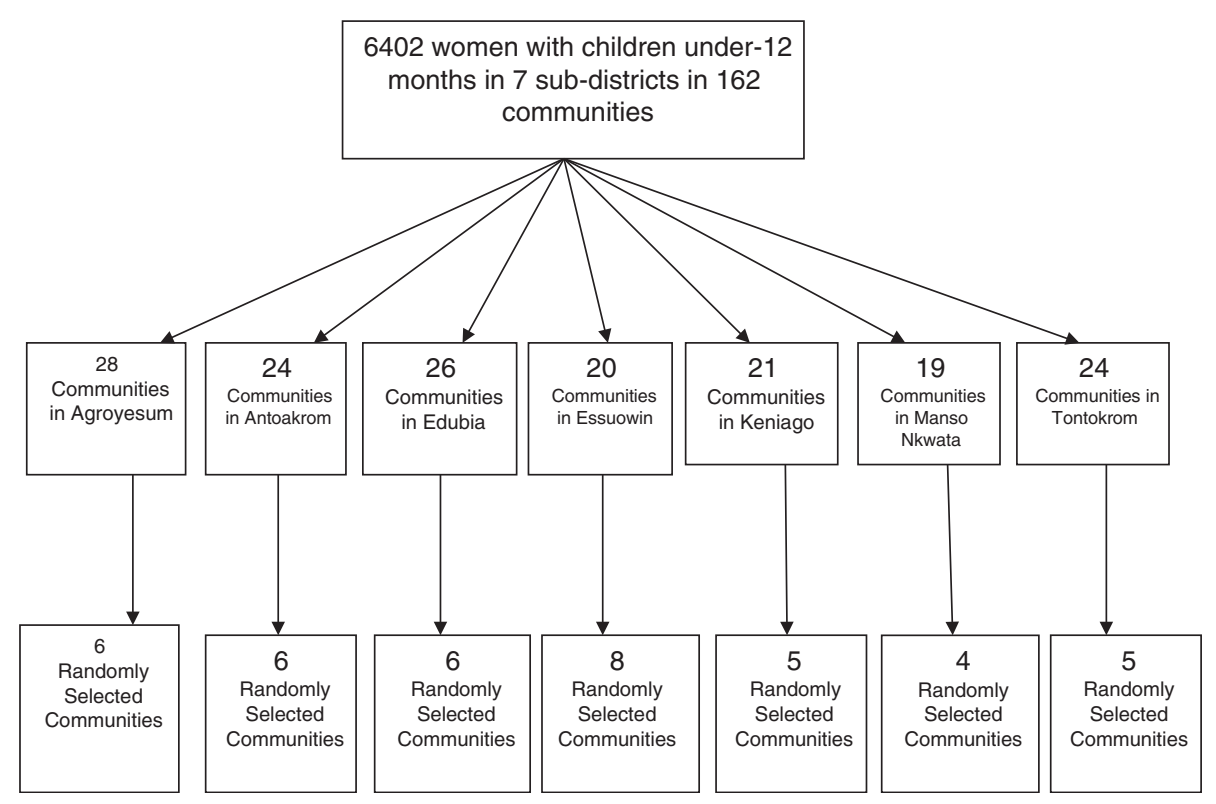

Fig. 1 Study design and sampling

birth attendants' services during delivery were elicited. The structured questionnaire was pre-tested in Abuoboso, a community with similar characteristics as the study communities.

\section{Operational definitions}

Birth preparedness and complication readiness (BPAR)

A pregnant woman is considered birth prepared if she and/or her family identifies a skilled birth attendant; identifies the location of the closest appropriate healthcare facility; has funds for birth-related and emergency expenses; has transport to the health facility for the birth and obstetric emergency, and has identified compatible blood donors in case of emergency [16].

Skilled birth attendant: persons with midwifery skills (doctor, nurse, midwives and health officer) who can manage normal deliveries and diagnose, manage or refer obstetric complications.

\section{Ethical consideration}

The Committee of Human Research, Publications and Ethics of the Kwame Nkrumah University of Science and Technology-School of Medical Sciences and Komfo Anokye Teaching Hospital, Kumasi, Ghana provided ethical approval for the study. Permission was obtained from the Amansie West District Health Directorate prior to the survey. Written informed or thumb print as well as verbal consent was obtained from all participants and no personal identifiers were collected.

\section{Data handling and statistical analysis}

Filled questionnaires were checked immediately for completeness and accuracy for each respondent survey for completeness. Data were entered into Microsoft Access (Redmond, WA, USA) and exported into STATA version 12 (College Station, TX, USA) for cleaning and analysis. Data were analyzed using survey-sampling weights. Each sub-district total population size was taken from the Ghana 2010 Housing and Population Census. Population level weights $\left(\mathrm{W}_{\mathrm{pi}}\right)$ and women in communities with children under 12 months weight $\left(\mathrm{W}_{\mathrm{wci}}\right)$ were estimated for each community. The overall weight $\left(\mathrm{W}_{\mathrm{TOTi}}\right)$ was obtained by multiplying $\mathrm{W}_{\mathrm{pi}}$ and $\mathrm{W}_{\mathrm{pci}}$. The knowledge level of participants on the risk of unskilled delivery was assessed using a Likert scale and described using the median value. Poor knowledge was considered below the median and high knowledge above the median.

Proportions were presented for categorical variables and their associations determined by Chi-square test. A logistic regression model was fitted to estimate independent associations between unskilled delivery and predictor variables that were independently significant $(p \leq 0.05)$ in the univariate analysis. In the subsequent steps, variables that were not predictors were entered into the final model one at a time and retained as multivariate predictors using the Hosmer-Lemeshow goodness-of-fit test. A backward stepwise analysis was performed containing all the variables to identify the variables that were removed from the model. The most non-significant variables were considered first for removal. A goodness-of-fit test using Hosmer-Lemeshow test was conducted and found that the final model was appropriate $(p=0.99)$. 


\section{Results}

The majority of the participants $(73.6 \%)$ were between 20 and 34 years, $90.9 \%$ were married and $46.6 \%$ lived within $5 \mathrm{~km}$ of a health care facility. The main occupation of many participants $(51.4 \%)$ were subsistence farming and $65.2 \%$ earned an average household income less than US\$1 per day (Table 1).

From Table 2, (97.7 \%) of the participants attended an antenatal care clinic (ANC) at least once, $75.1 \%$ had a minimum of 4 visits and most of the ANC services were provided by a midwife (91.4\%). Despite high ANC attendance, participants reported poor knowledge of risks associated with pregnancy (44.5\%). Although most participants reported knowing the benefits of skilled delivery (83.6 \%), $54.8 \%$ had ever delivered at least one of their children without a skilled care, and $42.3 \%$ reported delivering their most recent child without skilled care.

Figure 2 shows the proportion of unskilled and skilled deliveries. An average of $43.2 \%$ unskilled deliveries occurred without a skilled birth attendant in the district and $25.0 \%$ to $57.0 \%$ in the sub-districts. Each of the two intervention sub-districts, Keniago and Tontokrom had $42.0 \%$ deliveries while Edubia (non-intervention group) had the highest unskilled deliveries (56.7 \%). Edubia has a high number of trained TBAs in the district who are perceived by expectant mothers to be "good" and whose practices may be culturally sensitive and consistent with the belief system of the rural woman while Essuowin (51.3\% unskilled deliveries) had inadequate health facilities in this sub-district compared with the others and this may have influenced more births with an unskilled birth attendant in the area. Manso Nkwanta has experienced a high influx of people for small-scale mineral mining and coupled with a common practice of health workers to remind women to report to deliver without ANC history may have influenced the large gap between unskilled deliveries and institutional deliveries in Manso Nkwanta sub-district.

The main reasons for participants choosing unskilled delivery over a health facility with skilled delivery were 'insults from health staff' ( $23.5 \%)$, lack of transportation $(21.9 \%)$ and the availability of trained . traditional birth attendants and thus there was no reason to travel to access skilled delivery (17\%). Only $4.4 \%$ of women cited lack of money as a primary reason for not attending a health facility for birthing (Table 3).

Table 4 reports factors associated with place of delivery in a rural setting. In the multivariate analysis, women in the MVP intervention sub-districts were less likely to deliver with a skilled birth attendant or at a health facility when compared with women from other districts. Factors associated with utilization of skilled delivery care were having never had an
Table 1 Socio-demographic and socioeconomic characteristics of study sample

\begin{tabular}{|c|c|c|c|c|}
\hline \multirow[t]{2}{*}{ Characteristics } & \multicolumn{4}{|l|}{ Weighted } \\
\hline & $\begin{array}{l}\text { Non-MVP } \\
(n=29163) \%^{\mathrm{a}}\end{array}$ & $\begin{array}{l}\text { MVP } \\
(n=11341) \%^{\mathrm{a}}\end{array}$ & $\begin{array}{l}\text { Overall } \\
(n=40504) \%^{\mathrm{a}}\end{array}$ & $P$-value \\
\hline Age (Years) & & & & 0.36 \\
\hline $15-19$ & 12.3 & 10.5 & 11.8 & \\
\hline $20-34$ & 71.7 & 78.5 & 73.6 & \\
\hline $35-49$ & 16.0 & 10.9 & 14.6 & \\
\hline Marital status & & & & 0.01 \\
\hline Single $e^{* *}$ & 7.2 & 15.7 & 9.4 & \\
\hline $\begin{array}{l}\text { Married/ } \\
\text { Cohabitating }\end{array}$ & 92.7 & 84.9 & 90.9 & \\
\hline $\begin{array}{l}\text { Education } \\
\text { level }\end{array}$ & & & & 0.56 \\
\hline None & 22.3 & 20.2 & 21.8 & \\
\hline Primary & 19.3 & 26.8 & 21.4 & \\
\hline MS/JHS & 52.2 & 45.9 & 50.4 & \\
\hline SHS/above & 6.2 & 7.1 & 6.5 & \\
\hline \multicolumn{5}{|l|}{ Occupation } \\
\hline Farmer & 50.8 & 52.9 & 51.4 & 0.93 \\
\hline $\begin{array}{l}\text { Trading } \\
\text { (small scale) }\end{array}$ & 26.5 & 25.6 & 26.3 & \\
\hline Galamsey & 22.7 & 21.5 & 22.4 & \\
\hline $\begin{array}{l}\text { Number of } \\
\text { children alive }\end{array}$ & & & & 0.41 \\
\hline $1-2$ & 48.7 & 40.9 & 46.6 & \\
\hline $3-4$ & 28.7 & 32.8 & 29.8 & \\
\hline $5+$ & 22.6 & 26.3 & 23.7 & \\
\hline $\begin{array}{l}\text { Social } \\
\text { economic } \\
\text { atatus }\end{array}$ & & & & 0.68 \\
\hline Low & 53.4 & 55.9 & 54.1 & \\
\hline High & 46.6 & 44.1 & 45.9 & \\
\hline $\begin{array}{l}\text { Distance to } \\
\text { health facility }\end{array}$ & & & & 0.47 \\
\hline $0-5$ & 45.9 & 48.3 & 46.6 & \\
\hline $6-10$ & 37.4 & 40.0 & 38.1 & \\
\hline $11+$ & 16.7 & 11.7 & 15.3 & \\
\hline $\begin{array}{l}\text { Average } \\
\text { income of } \\
\text { mother } \\
\text { per day }\end{array}$ & & & & 0.001 \\
\hline $\begin{array}{l}<2 \text { Ghana } \\
\text { Cedis (\$1) }\end{array}$ & 60.0 & 78.7 & 65.2 & \\
\hline $\begin{array}{l}\text { 2-10 Ghana } \\
\text { Cedis (\$2-\$5) }\end{array}$ & 26.8 & 20.4 & 25.0 & \\
\hline $\begin{array}{l}>10 \text { Ghana } \\
\text { Cedis }(>\$ 10)\end{array}$ & 13.2 & 0.9 & 9.8 & \\
\hline
\end{tabular}

${ }^{a}$ The $\%$ shown is percentage of $n$; **Single includes divorced, separated and widow 
Table 2 Reproductive characteristics of mothers in Amansie West District, Ghana

\begin{tabular}{|c|c|c|c|c|c|}
\hline \multirow[t]{2}{*}{ Characteristics } & \multicolumn{2}{|l|}{ Unweighted } & \multicolumn{2}{|l|}{ Weighted } & \multirow[b]{2}{*}{$95 \% \mathrm{Cl}$} \\
\hline & Per cent \% & Frequency $n=400$ & Per cent \% & Frequency $(n=40504)$ & \\
\hline \multicolumn{6}{|l|}{ Received ante-natal care } \\
\hline Yes & 97.8 & 391 & 97.7 & 39583 & 96.2 to 99.2 \\
\hline No & 2.2 & 9 & 2.3 & 921 & 0.7 to 3.8 \\
\hline \multicolumn{6}{|l|}{ ANC provider } \\
\hline Doctor & 2.8 & 11 & 2.8 & 1121 & 1.2 to 4.4 \\
\hline Midwife & 91.0 & 364 & 91.4 & 37023 & 88.8 to 94.0 \\
\hline Auxiliary midwife/nurse & 4.5 & 18 & 4.0 & 1602 & 2.2 to 5.7 \\
\hline Relatives/Friends/Self & 1.8 & 7 & 1.8 & 758 & 0.4 to 3.3 \\
\hline \multicolumn{6}{|l|}{ Number of ANC visits } \\
\hline$<4$ Visits & 23.5 & 94 & 23.0 & 9118 & 18.9 to 27.2 \\
\hline $4+$ visits & 72.6 & 291 & 75.1 & 29724 & 70.9 to 79.3 \\
\hline Don't know & 3.9 & 15 & 1.9 & 741 & 0.7 to 3.2 \\
\hline \multicolumn{6}{|l|}{ Birth preparedness ${ }^{a}$} \\
\hline Yes & 60.8 & 242 & 62.4 & 25283 & 57.8 to 67.1 \\
\hline No & 39.2 & 158 & 37.6 & 15221 & 32.9 to 42.2 \\
\hline \multicolumn{6}{|c|}{ Knowledge of benefits of skilled delivery } \\
\hline Yes & 83.5 & 334 & 83.6 & 33853 & 79.9 to 87.2 \\
\hline No & 16.5 & 66 & 16.4 & 6651 & 12.7 to 20.1 \\
\hline \multicolumn{6}{|c|}{ Knowledge level of unskilled delivery } \\
\hline Poor knowledge & 44.8 & 179 & 44.5 & 18029 & 39.6 to 49.4 \\
\hline Good knowledge & 55.2 & 221 & 55.5 & 22475 & 50.6 to 60.3 \\
\hline \multicolumn{6}{|c|}{ Partner involved in decision making } \\
\hline Yes & 50.4 & 207 & 52.1 & 21098 & 47.1 to 57.1 \\
\hline No & 49.6 & 193 & 47.9 & 19406 & 42.9 to 52.9 \\
\hline \multicolumn{6}{|l|}{ Ever delivered at home } \\
\hline Yes & 54.3 & 217 & 54.8 & 22198 & 49.8 to 59.8 \\
\hline No & 45.8 & 183 & 45.2 & 18306 & 40.2 to 50.2 \\
\hline \multicolumn{6}{|l|}{ Place of delivery of last birth } \\
\hline Unskilled home delivery & 43.3 & 173 & 42.3 & 17126 & 37.4 to 47.2 \\
\hline Health facility skilled delivery & 56.7 & 227 & 57.7 & 23378 & 52.8 to 62.6 \\
\hline
\end{tabular}

${ }^{a}$ Birth preparedness, women expected to identify five basic actions they did before delivery: 1. identified a skilled birth attendant, 2 . identify the location of the closest appropriate care facility, 3. raising funds for birth-related and emergency expenses, 4. arrangement for transport to a health facility for the birth and obstetric emergency and 5. Identification of compatible blood donors in case of emergency

unskilled delivery, and attending four (4) or more ANC sessions. In contrast, those who lived far away from a facility (aOR $=0.32 ; 95 \%$ CI $0.13-0.74)$, lacked partner involvement $(\mathrm{aOR}=0.03 ; 95 \% \mathrm{CI}$ 0.01-0.06), and lacked knowledge of the benefits of skilled delivery $(\mathrm{aOR}=0.37 ; 95 \%$ CI $0.11-1.20)$ were less likely to delivery at a health facility.

\section{Discussion}

This study aimed to assess the effect of the MVP on the uptake of skilled delivery care and to identify factors associated with unskilled delivery in a rural district in
Ghana. In the 5 years between implementation of the MVP intervention package and subsequent survey, a notable uptake of skilled delivery has been observed. Across the district, unskilled deliveries decreased by $27.8 \%$ across the district. Even though Keniago and Tontokrom were sub-districts that had the intervention package, unskilled deliveries reduced by only $23.0 \%$. There still remained the common practice of not accessing the services of skilled attendants in spite of the availability of the services. However, Amansie West district as a whole has experienced a decline in unskilled delivery. 


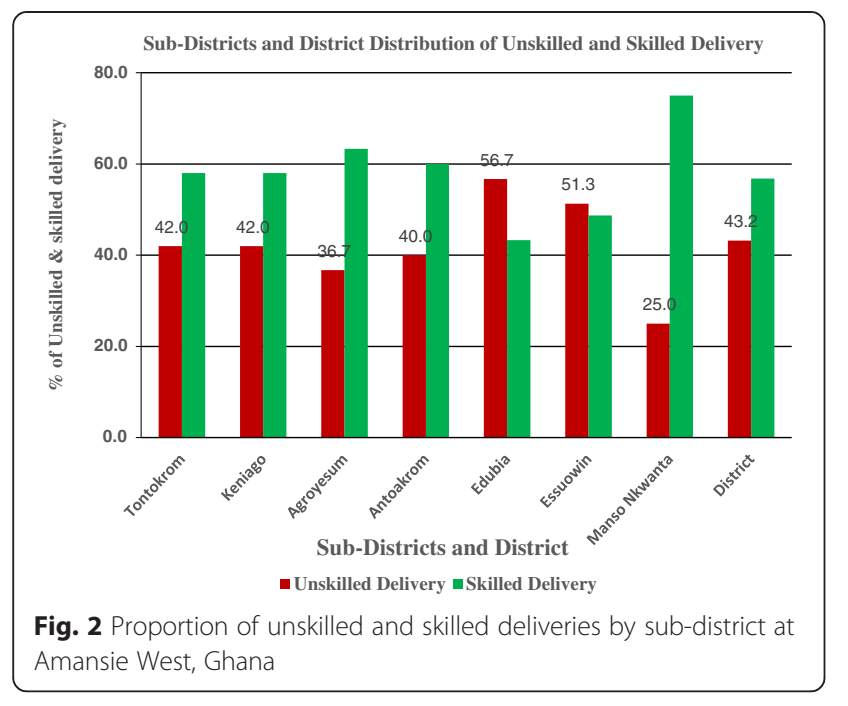

Factors that enhance the use of skilled delivery services The continuous use of unskilled deliveries in the MVP intervention communities suggests that merely making quality obstetric care services available is not enough to influence higher uptake of supervised delivery services, similar to previous reports in rural areas in LMIC [17-19]. Despite the high ANC visits by expectant mothers in this study, acceptability to use health facilities during deliveries is low in the rural communities in LMICs [20]. Affordability and availability were previously reported $[6,21,22]$ to increase access to skilled birth attendants in rural LMIC. In this study, we reported only $4.4 \%$ of mothers who could not access skilled delivery due to financial difficulties. It is therefore imperative to understand why many expectant mothers would still choose to deliver without skilled care in spite of the very high chance of maternal complications and/ or death. The success or failure of any public health program depends largely on the public's effective use of the services offered. Majority of the participants had only basic or no education and may not totally appreciate the benefits of skilled delivery at a health facility. Many human factors can also thwart access and use of curative medications in resource-poor settings, including traditional beliefs, illiteracy, and fatalistic attitudes. We observed that many participants' knowledge regarding benefits of skilled delivery and the risks involved in unskilled delivery was rather poor.

Some of the main reasons reported by mothers for choosing unskilled delivery over a skilled facility were; poor attitude and verbal abuse from the skilled service providers, transportation challenges, and the availability of a trained traditional birth attendant in their community. Negative previous experiences from service providers might have deterred some of the women from using skilled birth attendants $[23,24]$.
Training of staff on customer care and cross-culture communication can be used to enhance effective communication between health workers and clients to remove the latter's fear of unpleasant attitude of the former. Mwifadhi et al. [23] found lack of money, sudden onset of labour, tradition and culture as determinants for the place of delivery. The presence of a network of trained TBAs in the communities has given an alternative source of services to a health facility with little or no access cost. It is obvious that persistent health education is crucial to ensure effective use of the services offered, especially to those at risk. MVP intervention might not have considered health education as a tool to the deployment of the intervention. One other way to reducing unskilled deliveries substantially in rural settings is to identify, train and incentivize TBAs to refer all women requiring obstetric services to the nearest health facility. This can be effective and sustainable if an incentive package is tied to the number of cases TBAs refer to a health facility to guarantee their livelihood. This is consistent with other studies in LMICs that reported the strong position of TBAs in communities in which they operate as the preferred service provider because of their cultural sensitivity, easy availability and cheaper service [24, 25]. Cost and distance to the health facility were the two least reported problems by mothers in Amansie West District.

Despite the fact that most of the women were very close to skilled care $(<5 \mathrm{~km})$, nearly half of the women used unskilled delivery services. This indicates that some pre-hospital care services, local improvisations should be considered.

\section{Effect of Millenium Village Project (MVP) Intervention}

Five years into the intervention, the two intervention sub-districts Keniago and Tontokrom were still recording high (42.0 \%) deliveries outside health facilities, similar to the overall district average of $43.2 \%$. It was

Table 3 Primary reasons stated for home delivery

\begin{tabular}{lcllll}
\hline Reasons & \multicolumn{3}{l}{ Unweighted } & & Weighted \\
\cline { 2 - 3 } \cline { 5 - 6 } \cline { 5 - 6 } & Per cent \% & $\begin{array}{l}\text { Frequency } \\
(n=173)\end{array}$ & & Per cent \% & $\begin{array}{l}\text { Frequency } \\
(n=17126)\end{array}$ \\
\hline Insults & 23.7 & 41 & & 23.5 & 4023 \\
No transport & 21.4 & 37 & & 21.9 & 3756 \\
TBA is good & 17.3 & 30 & & 17.9 & 3073 \\
Cultural beliefs & 13.9 & 24 & & 13.5 & 2318 \\
Sudden labour & 6.9 & 12 & & 7.4 & 1264 \\
Delay & 5.8 & 10 & & 5.9 & 1015 \\
Poor service & 5.2 & 9 & & 4.1 & 700 \\
No money & 4.6 & 8 & & 4.4 & 753 \\
Long distance & 1.2 & 2 & & 1.3 & 225 \\
\hline
\end{tabular}


Table 4 Factors associated with place of delivery in a rural setting $^{\text {a }}$

\begin{tabular}{|c|c|c|}
\hline Characteristics & Unadjusted OR(95 \% Cl) & Adjusted OR(95\% C \\
\hline \multicolumn{3}{|l|}{ Intervention } \\
\hline Non-MVP sub-districts & 1.00 & 1.00 \\
\hline MVP sub-districts & $1.02(0.63,1.62)$ & $0.48(0.19,1.22)$ \\
\hline \multicolumn{3}{|c|}{ Socio-demographic and socio-economic factors } \\
\hline \multicolumn{3}{|l|}{ Age group } \\
\hline 15-19 & $0.87(0.47,1.62)$ & $0.47(0.15,1.49)$ \\
\hline $20-34$ & 1.00 & 1.00 \\
\hline $35-49$ & $1.12(0.63,2.01)$ & $3.12(0.91,10.65)$ \\
\hline \multicolumn{3}{|l|}{ Marital status } \\
\hline Married & 1.00 & 1.00 \\
\hline Single & $0.7(0.36,1.38)$ & $3.32(0.91,12.03)$ \\
\hline \multicolumn{3}{|l|}{ Education Level } \\
\hline None & 1.00 & \\
\hline Primary & $1.01(0.54,1.87)$ & \\
\hline $\begin{array}{l}\text { Middle/Junior high } \\
\text { School }\end{array}$ & $1.73(1.02,2.92)$ & \\
\hline SHS/above & $1.59(0.63,4.00)$ & \\
\hline \multicolumn{3}{|l|}{ Occupation } \\
\hline Farmer & 1.00 & \\
\hline Business & $1.98(1.13,3.06)$ & \\
\hline Galamsey & $1.52(0.91,2.54)$ & \\
\hline \multicolumn{3}{|l|}{ Number of children } \\
\hline $1-2$ & 1.00 & \\
\hline 3-4 & $0.73(0.45,1.16)$ & \\
\hline $5-6$ & $0.80(0.48,1.33)$ & \\
\hline \multicolumn{3}{|c|}{ Average household income per day } \\
\hline$\$ 1$ & 1.00 & \\
\hline$\$ 2-\$ 5$ & $1.48(0.91,2.42)$ & \\
\hline$\$ 5$ & $2.49(1.15,5.41)$ & \\
\hline \multicolumn{3}{|l|}{ Client factors: } \\
\hline \multicolumn{3}{|l|}{ Distance } \\
\hline$\leq 5$ & 1.00 & 1.00 \\
\hline $6-10$ & $0.45(0.29,0.71)$ & $0.32(0.13,0.74)$ \\
\hline 11-15 & $0.52(0.28,0.97)$ & $0.40(0.11,1.46)$ \\
\hline \multicolumn{3}{|l|}{ Birth preparedness } \\
\hline Yes & 1.00 & 1.00 \\
\hline No & $0.05(0.03,0.09)$ & $0.05(0.02,0.13)$ \\
\hline \multicolumn{3}{|c|}{ Partner involvement in decision making } \\
\hline Involved & 1.00 & 1.00 \\
\hline Not involved & $0.02(0.01,0.04)$ & $0.03(0.01,0.06)$ \\
\hline \multicolumn{3}{|c|}{ Ever had unskilled delivery } \\
\hline Yes & 1.00 & 1.00 \\
\hline No & $5.19(3.31,8.13)$ & $6.55(2.47,17.34)$ \\
\hline
\end{tabular}

Table 4 Factors associated with place of delivery in a rural setting ${ }^{\text {a }}$ (Continued)

\begin{tabular}{lcl}
\hline Knowledge of benefits of skilled delivery & \\
Yes & 1.00 & 1.00 \\
No & $0.07(0.03,0.15)$ & $0.37(0.11,1.20)$ \\
Number of ANC visits & \\
$<4$ & 1.00 & 1.00 \\
$\geq 4$ & $3.32(2.04,5.41)$ & $1.36(0.51,3.62)$ \\
\hline${ }^{a}$ Table 4 estimates weighted for sampling probability &
\end{tabular}

hypothesized that the MVP intervention, in the two subdistricts would result in a greater proportion of women utilizing healthcare facility for delivery compared with the other sub-districts in the District [12]. However, only two non-intervention sub-districts, Edubia and Essuowin, had higher unskilled deliveries than the two intervention sub-districts. The other three non-intervention subdistricts that recorded lower unskilled deliveries may have some inherent advantages that the rest of the sub-districts did not have. These could include better maternal health seeking behavior, higher income levels, higher education status and healthy provider-client relationship among others. The two sub-districts of Keniago and Tontokrom, may have peculiar characteristics and obstacles other than those mitigated by the intervention package and which were not accounted for by the intervention. No single intervention therefore, is appropriate in all contexts. Interventions should be adapted to specific local ecological, epidemiological, economic, and social conditions. Campbell et al. [26] stated that there are many single interventions available, but none alone can effectively achieve the high coverage expected [27]. It is in this regards that one had to evaluate the adequacy of interventions put in place to enhance utilization of healthcare facilities for delivery.

\section{Maternal mortality ratio with the introduction of MVP}

As anticipated, maternal mortality ratio in the entire Amansie West District decreased in accordance with the decrease in percentage of unskilled births between 2007 and 2011, except for 2010 when unskilled delivery rates declined by 11.8 percentage points from the preceding year while the maternal mortality increased by 5 deaths per 100,000 births in the same time frame. While this overall drop in the maternal mortality ratio is certainly encouraging, it does not give enough insight into how maternal mortality ratios in Keniago and Tontokrom were influenced by the use of skilled delivery services or how they influenced the overall trend of decreasing maternal mortality in Amansie West [14].

In this study nearly all the women had at least one ANC visit with majority of them making either four or 
more visits. This however did not translate into high skilled delivery as reported by similar studies [28, 29]. High ANC visits by the women do present opportunity for health education on risks and complications for both the mother and the unborn child during the pregnancy [25]. Single mothers and older women (35-49 years) were three times more likely to use unskilled services compared with married and younger women. Women who had ever used unskilled attendants during delivery were six times more likely to have an unskilled delivery than those who used skilled delivery services in a health facility. Women who prepared resources for birth were more likely to deliver at a health facility. Hence, birth preparedness is a preventive behavior [26, 28, 30-32] implying that adequate knowledge on pregnancy and delivery could strongly influence uptake of skilled delivery [29]. Partner involvement in decision making influenced place of delivery and this finding was consistent with studies in Ethiopia, Kenya and Vietnam [33, 34].

\section{Strengths and limitations}

This study provides data on factors influencing the choice of place of delivery in rural Ghana. In particular, it provides contextual factors influencing the utilization of skilled obstetric care which can inform policy programming and appropriate intervention. We were however unable to draw direct attribution of institutional factors, content and quality of antenatal and delivery care benefit to the outcome of this evaluation in a cross sectional study. The sample of women seeking postpartum care excluded other women who may have different characteristics from those attending the clinics. These do not render the study results invalid.

\section{Conclusion}

The significant investment and intervention package made by MVP to reduce the barriers to accessing skilled obstetric care and delivery, may have contributed to an improvement in the uptake of skilled delivery after five years of intervention across the district. However some subdistricts did not show marked improvements. Maternal factors such as age, education, marital status, occupation, ever used unskilled delivery services, number of ANC visits, partner support and the services of TBA in the communities were more likely to influence choice of place of delivery. Additionally, the lack of knowledge of the benefits of skilled delivery and, verbal abuse and poor attitude experienced from skilled birth attendants deterred expectant mothers from accessing skilled delivery. The success of this health intervention would depend largely on the effective public education and communication among health workers and clients.

\section{Abbreviation}

LMICs: Low-and middle income countries; TBAs: Traditional birth attendants; MDG: Millenium Development Goal; NHIS: National Health Insurance Scheme; MVP: Millenium villages project; ANC: Antenatal care; MMR: Maternal mortality ratio; CWCs: Child welfare clinic.

\section{Competing interests}

The authors declare that they have no competing interests.

\section{Authors' contributions}

EKN and JTS were involved in the design and implementation of the study, field work, data management, analysis, interpretation of the data, and writing of the manuscript. EKN performed the statistical analysis. EKN, JTS and HL wrote the first draft of the paper. EO, VMD and EOD provided significant input to the manuscript, revised it critically for important intellectual content, and gave their final approval for the version to be published. All authors have read and approved of the final manuscript.

\section{Acknowledgements}

This study was supported by the District Director of Health Services (DDHS) of the Amansie West District and the District Health Management Team (DHMT). We also appreciate the contribution of Mr. Gordon Sakyi, Mr. Danie Boakye and Mr. Godfred Kojo Imoro for their incalculable assistance during the data collection. The content of this manuscript are the sole responsibility of the authors and does not necessarily represent the official views of the Millenium Villages Project of Ghana. The authors thank all data collectors for their assistance with field visits. In addition, we acknowledge the time and effort contributed by the participants.

\section{Author details}

${ }^{1}$ School of Public Health, Department of Population, Family and Reproductive Health, Kwame Nkrumah University Science and Technology, PMB, Kumasi, Ghana. ${ }^{2}$ Henry Ford Health System, Department of Public Health Sciences, Detroit, MI, USA. ${ }^{3}$ Department of Nursing, Faculty of Allied Health Sciences, Kwame Nkrumah University of Science and Technology, Kumasi, Ghana. ${ }^{4}$ Sekyere-Kumawu Health Directorate, Box 40, Kumasi, Ghana. ${ }^{5}$ School of Public Health, Department of International and Global Health, KNUST, Kumasi, Ghana. 'Kumasi Collaborative Center for Tropical Research, Kumasi, Ghana.

Received: 5 February 2014 Accepted: 2 October 2015

Published online: 07 October 2015

\section{References}

1. Ronsmans C, Graham WJ. Lancet Maternal Survival Series steering g: Maternal mortality: who, when, where, and why. Lancet. 2006;368(9542):1189-200.

2. Lawn JE, Cousens S, Zupan J. Lancet Neonatal Survival Steering T: 4 million neonatal deaths: when? Where? Why? Lancet. 2005;365(9462):891-900

3. Ghana Health Service (GHS). 2011 Annual Report. Accra, Ghana: Ghana Health Service; 2011.

4. Service, GS. Multiple Indicator Cluster Survey with an enhanced Malaria Module and Biomarker 2011, Final Report. Accra, Ghana: Ghana Statistical Service; 2011.

5. Ronsmans C, Etard JF, Walraven G, Hoj L, Dumont A, de Bernis L, et al. Maternal mortality and access to obstetric services in West Africa. Trop Med Int Health. 2003;8(10):940-8.

6. Isaac A. Determinants of use of maternal-child health services in Rural Ghana. J Biosoc Med. 2000;312:1-15.

7. Ransom E, Yinger N. Making motherhood safer; overcoming obstacles on the pathway to care. USA: Population Reference Bureau; 2002.

8. Collender G, Gabrysch S, Campbell OM. Reducing maternal mortality: better monitoring, indicators and benchmarks needed to improve emergency obstetric care. Research summary for policymakers. Trop Med Int Health. 2012;17(6):694-6.

9. National Helath Insurance Authority(NHIS): Annual report 2009. 2009

10. Blanchet NJ, Fink G, Osei-Akoto I. The effect of Ghana's National Health Insurance Scheme on Health Care Utilization. Ghana Med J. 2012:46(2):76-84.

11. Asamoah BO, Moussa KM, Stafstrom M, Musinguzi G. Distribution of causes of maternal mortality among different socio-demographic groups in Ghana; a descriptive study. BMC Public Health. 2011;11:159. 
12. Millennium Villages, Bonsaaso, Ghana. www.millenniumvillages.org/the-villages/ bonsaaso-ghana.

13. Ghana Statistical Service (GSS). 2010 Population \& Housing Census: Summary Report of Final Results. 2012.

14. Amansie West District Health Directorate. Annual Report 2010. In.: DHMT-Manso Nkwanta; 2010

15. The Millenium Villages Project. Bonsaaso, Ghana Cluster; In conjuntion with the Amansie West District Assembly. Project Report 2006-2011 In.; 2012.

16. Mihret H, Mesganaw F. Birth Preparedness and Complication Readiness among women in Adigrat town, North Ethiopia. Ethiop J Health Dev. 2007;22(1):14-20.

17. Benedict OA, Anette A, Karen Odberg P, Per-Olof O. Magnitude and trends of inequalities in antenatal care and delivery under skilled care among different socio-demographic groups in Ghana from 1998-2008. BMC Pregnancy and Childbirth. 2014;14:295.

18. Carter A, Jamal O, Odoch P, Mohammed K. Factors That Contribute to the Low Uptake of Skilled Care During Delivery in Malindi, Kenya. Health and Development program. Kenya: ISP Collection; 2010.

19. Magoma M, Requejo J, Campbell O, Cousens S, Filippi V. High ANC coverage and low skilled attendance in a rural Tanzanian district: a case for implementing a birth plan intervention. BMC Pregnancy and Childbirth. 2010;10:13.

20. Silal SP, Penn-Kekana L, Harris B, Birch S, Mclntyre D. Exploring inequalities in access to and use of maternal health services in South Africa. BMC Health Services Res. 2012;12:120.

21. Daniel B. Analysing the primacy of distance in the utilization of health services in the Ahafo-Ano Sourth district, Ghana. Int J Health Plann Manage. 2003;18(4):293-311.

22. Ghana Statistical Service GSS, Ghana Health Service (GHS), ICF Macro. Demographic and Health Survey. Accra, GHana: GSS, GHS and ICF Macro; 2009.

23. Mwifadhi M, Joana AS, Adiel KM, Bright $\mathrm{O}$, Hassan M, Marcel T, et al. Factors affecting home delivery in rural Tanzania. Trop Med Int Health. 2007;12(7):862-72.

24. Warren C. Care seeking for maternal health: challenges remain for poor women. Ethiopian J Health. 2010;24(special issue 1):100-104.

25. Lindsey Ann L, Rob BS. Utilization of maternal health care services in the department of Matagalpa, Nicaragua. Pan Am J Public Health. 2008;24(2):75.

26. Berhan $Y$, Abdel A. Emergency obstetric performance with emphasis on operative delivery outcome: Does it reflect the quality of care? Ethiop J Health Dev. 2004;18(2):96-106.

27. Oona MR C, Wendy KG, group ObotLMSSs. Strategies for reducing maternal mortality: getting on with what works. Lancet. 2006;6736(6):69381-1.

28. Elizabeth I, Ransom YN. Making motherhood safer, overcome obstacles on the pathway to care. Population Reference Bureau. Prb website. Available: http://www.prb.org/pdf/makMotherhdSafer_Eng.pdf Accesses 2013 Dec 22. 2002.

29. Fantu A, Yemane B, Belaineh G. Factors associated with home delivery in Bahirdar, Ethiopia: a case control study. BMC Res Notes. 2012;5:563.

30. Dipty N, Srinivas G. Birth preparedness and its effecton place of delivery and post-natal check-ups in Nepal. PloS ONE. 2013;8:5.

31. McPherson R, Khadka N, Moore J, Sharma N. Are Birth-preparedness Programmes Effective? Results from a Field Trial in Siraha District Nepal. J Health Popul Nutr. 2006;24(4):479-88.

32. Moran A, Sangli G, Dineen R, Rawlinns B, Yameogo M. Birth-preparedness for maternal health: findings from Koupela district, Burkina Faso. J Health Popul Nutr. 2006;24(4):489-97.

33. Mekonnen Y. Pattern of maternity care utilization in southern Ethiopia: evidence from community and family survey. Ethiopian J Health Dev. 2003;17(1):27-33.

34. Mona M, Rebecca C, Isabella C, Donna P, Marcia G. A behavior change's approach to Investigating factors influencing women's use of skilled care in Homa Bay District Kenya. In: The CHANGE project, Academy for Educational Development. Washington DC: The Man off Group; 2002.

\section{Submit your next manuscript to BioMed Central and take full advantage of:}

- Convenient online submission

- Thorough peer review

- No space constraints or color figure charges

- Immediate publication on acceptance

- Inclusion in PubMed, CAS, Scopus and Google Scholar

- Research which is freely available for redistribution

Submit your manuscript at www.biomedcentral.com/submit 